This PDF is a selection from a published volume from the National Bureau of Economic Research

Volume Title: Frontiers in Health Policy Research, Volume 5

Volume Author/Editor: Alan M. Garber, editor

Volume Publisher: MIT Press

Volume ISBN: 0-262-07234-3

Volume URL: http://www.nber.org/books/garb02-1

Conference Date: June 7, 2001

Publication Date: January 2002

Title: Tax Credits, the Distribution of Subsidized Health Insurance Premiums, and the Uninsured

Author: Mark V. Pauly, Bradley Herring, David Song

URL: http://www.nber.org/chapters/c9859 


\section{Tax Credits, the Distribution of Subsidized Health Insurance Premiums, and the Uninsured}

Mark V. Pauly, Department of Health Care Systems, University of Pennsylvania

Bradley Herring, Institution for Social and Policy Studies, Yale University

David Song, Department of Health Care Systems, University of Pennsylvania

\section{Executive Summary}

This paper investigates the impact of a $\$ 1,000$ refundable tax credit for self-only coverage on net premiums and insurance purchases for a representative sample of potential buyers in the individual insurance market. Two methods are used to estimate the distribution of premiums: predicted premiums based on a sample of actual purchasers, and premium quotations drawn from an e-insurance web site. In most of the simulations, the net premiums for half or more of the prospective buyers are reduced to zero or low levels. The number of uninsured is reduced by 21 to 85 percent, depending on the size of the deductible in the benchmark plan. However, the results are sensitive to assumptions about insurer underwriting practices.

\section{Introduction}

One way to reduce the number of uninsured Americans is to help them pay private health insurance premiums. Proposals for refundable tax credits, such as those from the Bush administration or from members of Congress, would offer many people credits or vouchers that could cover part or all of premiums. For most of the currently uninsured, the most convenient and most likely place to obtain insurance is the individual market, and sometimes proposed credits would be limited to use in such markets.

A key to understanding the possible impact of credits of different amounts on insurance purchases is estimation of the extent to which they reduce "net" premiums-the market premium minus the credit-to moderate levels. Previous work has indicated that reasonably generous credits, on the order of about 50 percent of an average premium, might reduce the number of uninsured by half or more. ${ }^{1}$ 
However, the measures of premiums in those studies were based largely on estimates of individual insurance premiums generated by applying industry-average administrative loading factors to expected or average expenses, and the credit plans were hypothetical or sample plans. An alternative strategy is to develop direct measures or estimates of premiums that would be or have been charged in real-world markets, apply the actual credits that would be offered under a specific legislative proposal (or variation thereof), and calculate the net premium. One can then estimate the demand for insurance at that net premium. For people for whom the net premium is zero (credit exceeds market premium), one would expect high, almost universal demand; for people whose net premiums remain positive, estimates of the effect of subsidized premium levels on the demand for insurance can generate estimates of the number of people who would be willing to buy at least some insurance coverage at that price.

\section{What Is the Price of Individual Insurance?}

Only about 6 percent of Americans obtain private health insurance in individual insurance markets. There are two commonly remarked characteristics of such insurance. First, industry-level data suggest that premiums are high relative to money benefits received. Since the primary benefit from insurance is the payment for medical services, these data suggest that nongroup insurance is (relative to group insurance) generally expensive for what one gets. It is widely believed that this high "price" for benefits partially explains why only about one-quarter of those who are not already covered by group or public insurance choose to buy nongroup coverage. Second, it is commonly believed that persons with higher expected expenses pay higher premiums in the individual market. Pauly and Herring showed that this is only partially true: premiums paid are higher for higher risk people, but they increase significantly less than proportionally with premiums. They increase with individual age and the costliness of the local health care market, but (given age and location) they are not significantly higher for people with chronic conditions or other high risk characteristics. ${ }^{2}$ Pauly and Herring attribute some of this behavior to the widespread prevalence of guaranteed renewability provisions in individual insurance policies. They do find, however, that premiums paid for similar policies vary substantially for reasons unrelated to observable risk.

These observations suggest that it would be desirable to relate credits to the premiums people pay or would pay in the individual market, 
as well as estimating the likelihood of purchase (or the proportion purchasing) based on those net premiums and a model of the demand for insurance. This is the task we perform in this paper. Specifically, we will explore the impact on the net premium for self-only coverage of flat dollar credits at a level of $\$ 1,000$. This credit can be claimed for either individual or group coverage. In the latter case, any tax subsidy would be subtracted from the credit to be offered. We focus on the use of the credit in the individual market. The conventional estimate of the nongroup premium for comprehensive self-only coverage is about $\$ 2,500$, so such a credit would reflect an average subsidy of only 40 percent. Because actual premiums vary considerably across persons, however, the actual net premium can likewise vary. For the take-up rates presented in this paper, we examine long-run behavior so that any short-run "friction" in take-up rates is not considered. Also, while most proposals envision credits that phase out as income increases and that are different for family coverage, we assume for simplicity here that credits equal $\$ 1,000$ for all individuals.

Two populations are of interest here. The most obvious group to study is the population of people already purchasing individual coverage; for them, we know what insurance costs, and no estimation is involved. For this population, we use evidence from a survey of a representative sample of the U.S. population without group insurance to describe premiums paid and some characteristics of insurance purchased at those premiums. Second, the set of people who did not buy insurance is also important-precisely because this is the set of people whose insurance-purchasing behavior tax credits are supposed to affect. This population may have sought insurance but may have discontinued searching after confronting premiums higher than the premium they would have been willing to pay (their "reservation price"), or they may not have searched at all. We develop several methods to estimate the price (or distribution of prices) they would face.

Our work reported here supplements previous work by ourselves and others. ${ }^{3}$ Our earlier work based measures of gross premiums not on actual premium data but rather on estimates of premiums constructed using information about expected benefits and average administrative loading in the nongroup insurance market. However, the actual premiums people could pay or do pay may differ from these estimates because actual nongroup insurance premiums have a very wide dispersion about the average. ${ }^{4}$

The other approach to estimating individual insurance premiums is to use an average or median of premiums that insurers quote. In 2001, 
this approach yields an estimate of average annual premiums for self-only coverage of about $\$ 2,400$ per year. However, no rational buyer who has obtained price quotes would choose to pay the average or median price. Rather, the buyer would pay the lowest price (or something close to it). In short, the most relevant measure for the analysis of a tax credit is the premium actually paid by those who obtained insurance and the lowest premium the person would have found for those who do not purchase insurance. Either actual or potential transaction prices may differ substantially from the average or typical premium posted by insurers.

Our work reported in this paper generates estimates of net premiums paid or payable for a representative sample of those who currently do not obtain employment-based insurance coverage. This sample is obviously more relevant than two self-selected samples recently discussed in the literature. One is the sample of people who chose to purchase insurance on a large web site. ${ }^{5}$ Those who actually purchased may have been the lucky few who were able to find low premiums; others who visited the site may have seen premiums they regarded as high and therefore decided to remain uninsured. That is, the population of all purchasers and the premiums they paid may both differ from those for users of the site, and many current nonpurchasers would not have visited the site at all. In short, the sample of web site transactions, while instructive, cannot be assumed to be representative of potential nongroup insurance purchasers. The other sample is the "selected" sample in a small number of cities or in high-risk categories for which only family premiums have been investigated, and for which high premiums have been found. ${ }^{6}$ A more recent similar study presented premiums and coverages for a small number of hypothetical buyers (in a small number of cities) who list previous or current medical conditions on their insurance applications. ${ }^{7}$ Our sample is also superior to these two studies as a description of the effect of credits on the overall population of potential nongroup purchasers.

Another way in which this work differs from some common policy analyses is the treatment of tax credits in the case of people who face positive net premiums. A typical approach implicitly or explicitly judges the effectiveness of such a program by comparing the resulting net premiums to the person's income and judges insurance to be less "affordable," and therefore less likely to be purchased, if the net premium remains relatively high compared to income. ${ }^{8}$ However, there is more involved in the purchase of insurance than only this kind of 
affordability. Specifically, compared to people facing positive but lower premiums, a person would be expected to be more likely (than someone charged a lower premium) to purchase insurance even at a relatively high premium if the person expected substantially larger benefits from the insurance. Since higher premiums sometimes (although not always) reflect higher risk, we might expect that, at least up to a point, higher risk people would be likely to buy insurance at moderately high premiums if the insurance provides them with high levels of benefit payments and/or shields them from high levels of outof-pocket payment. Consistent with this argument, the data suggest that, even in the relatively low income (but not impoverished) population, the proportion of people obtaining insurance is actually relatively high among middle-aged people. ${ }^{9}$ Thus, translating net premiums into probabilities of purchase will be an important adjunct to the estimation of the determination of net premiums.

Therefore, we use several alternative estimates of the net price of individual insurance that a person might face. The most direct measures use actual premiums paid by a random sample of nongroup insurance purchasers. This sample illustrates the actual variation in premiums paid, variation that is related both to pricing/search behavior and to characteristics of insurance. For those who did not buy insurance, we use two approaches to estimate the premium they would have paid. In one, we use data on the characteristics of the uninsured to generate premium quotations from an online web site. We specify the level of coverage to be held constant, and we offer alternative simulations of purchasing behavior-selecting either the lowest decile of premiums or the premium at the lowest quartile. The second approach develops a premium prediction regression from the data on actual purchases and then uses this regression to predict premiums for the currently uninsured. (All of these approaches may be optimistic because we do not know the actual rejected premiums, if any, of those who did not purchase.)

It will be of interest to compare the net effect of various tax credits in states with community rating laws and states without such laws. If community rating laws reduce the extent to which premiums vary with risk (their intended purpose), they will reduce the proportion of a population with relatively high and relatively low net premiums. Determining the magnitude of the difference that laws actually make, and the implications of these differences for insurance purchasing, will be of value. 
If we generate a pattern of estimated net premiums for the uninsured, how can we determine whether they would be willing to buy coverage at those premiums? Just observing the distribution of net premiums can tell us a great deal. Those who face zero or nominal net premiums would be expected to take up the free or nearly free coverage. But what will the other people who face positive but subsidized premiums do?

The main approach we pursue here is to convert one of the distributions of net premiums into estimates of the distribution of insurance purchases. We assume that people whose credit equals or exceeds the premium for a given insurance policy, for whom the net price is zero, would prefer to obtain that policy rather than remain uninsured. For those with positive net premiums, we use the models developed by Pauly and Herring to estimate the probability or proportion of insurance purchasing. ${ }^{10}$

\section{Net Premiums Among Insureds}

We examine a sample of persons purchasing nongroup insurance provided by the 1996-1997 Community Tracking Survey (CTS), a large random household sample selected from a nationally representative set of communities. Within the set of all individuals, 1,050 nonelderly adult respondents reported purchasing nongroup insurance on a self-only basis. Of this set, 908 (86 percent) reported the premiums paid. All of these individuals are classified as "insured" in the analysis of the data. The 1996 premium data are "inflated" to 2001 insurance price levels by using an annual premium growth rate of 7 percent.

If we assume that each of these individuals would be eligible for a $\$ 1,000$ tax credit, the distribution of net premiums would be as indicated in table 4.1. Approximately 20 percent of these purchasers would pay a zero net premium. At the median net premium, the dollar amount is $\$ 809$ per year, which is 45 percent of the total premium. About 60 percent of all purchasers would have had their premium halved by a $\$ 1,000$ credit. We also split the sample at the median income and found essentially similar results for each subsample.

\section{Online Premiums for Nonelderly Uninsured Adults}

There were 6,083 nonelderly adults in the CTS sample who indicate that they currently had neither public nor private health insurance. We 
Table 4.1

Distribution of net premiums for nongroup self-only policies under fixed $\$ 1,000$ tax credit plan

\begin{tabular}{lccc}
\hline & Actual premium & Net premium (NP) & $\begin{array}{l}\text { NP as a percentage } \\
\text { of original premium }\end{array}$ \\
\hline Mean & $\$ 1,989$ & $\$ 1,122$ & 36 \\
10th percentile & $\$ 708$ & $\$ 0$ & 0 \\
25th percentile & $\$ 1,088$ & $\$ 88$ & 8 \\
50th percentile & $\$ 1,809$ & $\$ 809$ & 45 \\
75th percentile & $\$ 2,753$ & $\$ 1,753$ & 64 \\
90th percentile & $\$ 3,932$ & $\$ 2,932$ & 75 \\
\hline
\end{tabular}

Representative sample of 821 nongroup policyholders in the CTS household survey (1996-1997).

identified a comprehensive (indemnity or PPO) medical-surgical plan with annual deductibles less than or equal to $\$ 1,000$, or an $\mathrm{HMO}$ with similar or lower deductibles. We then examined the publicly available online premium quotations available from the e-healthinsurance web site (www.ehealthinsurance.com) that would be available to the survey respondents given their age, gender, smoking behavior, and zip code location.

The lowest premium plan that meets these criteria is certainly a possible choice. If its premium were less than or close to the credit, it surely would be preferable to the no-insurance option. In many cases, however, the absolute lowest priced plan that meets the deductible specification also has other exclusions; for instance, it may exclude coverage of nonsurgical routine outpatient care entirely. Accordingly, we show the net premium at the 10th and 25th percentile of the distribution of premiums.

We were able to match 72 percent $(\mathrm{N}=4,383)$ of the CTS sample with web premiums. Failure to match usually was due to missing CTS data (for example, smoking behavior), or to the absence of a web insurance option in the sample person's zip code. The geographic patterns themselves are of interest. Web premiums were more likely to be missing for people who lived in community rating states. The form of community rating varies across the states that require it, with only New York and New Jersey using pure community rating. Of the nine states identified as community rating states with cities in the CTS sample (New York, New Jersey, Washington, Massachusetts, Kentucky, North Dakota, New Hampshire, Maine, and Vermont), there were no web site 
premiums available in six. In New York, the highest deductible listed was $\$ 250$. In the remaining community rating states (Washington and New Jersey), median premiums were about three times higher than in other states, presumably reflecting both higher premiums for given coverage and less availability of high-deductible options. For example, deleting the community rating states from table 4.1 would cut the net premium at the 50 th percentile in half.

Results of the analysis on the complete matched data set are shown in tables 4.2 and 4.3 . For the population of potential insurance purchasers, the 10th percentile net premiums for insurance obtained from the web are zero or close to zero for 50 to 75 percent of all such persons. As in table 4.1 , the top 10 percent of net premiums are quite large, reflecting both the absence of a high-deductible option and high overall health insurance premiums in some locations. If we move up the frequency distribution of premiums to the 25 th percentile, there is still a sizeable proportion of the uninsured who can obtain insurance for free and must pay net premiums that are a small fraction of the total. The net premium at the 50 th percentile is $\$ 252$.

\section{Estimating Premiums for the Uninsured Based on Transactions Data}

The third approach to generating a distribution of net premiums assumes that uninsured persons would have available to them the same premiums as those with similar characteristics who actually purchased insurance. This approach also assumes that the uninsured would have the same preferences for plan types and the same search behavior as those who actually purchased. In reality, the uninsured probably would search less, but they might also might seek less coverage than those who purchased.

To generate a distribution of premiums, we first regress the premiums paid by purchasers on purchaser characteristics. Table 4.4 shows the result of such a regression. The most important predictive variables turn out to be age, race, and community location. Given the distribution of characteristics of the uninsured, we then generate a distribution of predicted or average premiums. Table 4.5 shows the distribution of net premiums based on this approach. The distribution (perhaps not surprisingly) is fairly close to the distribution of paid premiums, but with a somewhat larger proportion of the population facing low net premiums (since more of the uninsured are young). ${ }^{11}$ 
Table 4.2

Distribution of net 10th percentile online premiums for uninsured individuals, under fixed $\$ 1,000$ tax credit plan

\begin{tabular}{lccl}
\hline & & & $\begin{array}{l}\text { NP as a percentage } \\
\text { of original } \\
\text { premium }\end{array}$ \\
\hline Mean & $\$ 1,326$ & Net premium (NP) & $\begin{array}{l}\text { premium } \\
\text { 10th percentile }\end{array}$ \\
25th percentile & $\$ 640$ & $\$ 0$ & 0 \\
50th percentile & $\$ 984$ & $\$ 0$ & 0 \\
75th percentile & $\$ 1,791$ & $\$ 0$ & 0 \\
90th percentile & $\$ 2,884$ & $\$ 791$ & 44 \\
\hline
\end{tabular}

Representative sample of 4,383 uninsured individuals in the CTS household survey (1996-1997). For each individual, the online premium reflects the 10th percentile premium for a menu of individual health insurance plans (whose deductibles are no greater than $\$ 1,000$ ) in the corresponding locale. Premium quotes were obtained from www.ehealthinsurance.com.

\section{Table 4.3}

Distribution of net 25th percentile online premiums for uninsured individuals, under fixed $\$ 1,000$ tax credit plan

\begin{tabular}{lccc}
\hline & Online premium & Net premium (NP) & $\begin{array}{l}\text { NP as a percentage } \\
\text { of original premium }\end{array}$ \\
\hline Mean & $\$ 1,631$ & $\$ 710$ & 27 \\
10th percentile & $\$ 683$ & $\$ 0$ & 0 \\
25th percentile & $\$ 873$ & $\$ 0$ & 0 \\
50th percentile & $\$ 1,252$ & $\$ 252$ & 20 \\
75th percentile & $\$ 1,995$ & $\$ 995$ & 50 \\
90th percentile & $\$ 2,952$ & $\$ 1,952$ & 66 \\
\hline
\end{tabular}

Representative sample of uninsured individuals in the CTS household survey (1996-1997). For each individual, the online premium reflects the 25th percentile premium for a menu of individual health plans (whose deductibles are no greater than $\$ 1,000$ ) in the corresponding locale. Premium quotes were obtained from www. ehealthinsurance.com. 
Table 4.4

Regression analysis of the determinants of health insurance premiums, population ages 18-64 with nongroup coverage ${ }^{a}$

\begin{tabular}{|c|c|}
\hline Variable & Coefficient \\
\hline \multicolumn{2}{|l|}{ Male Age } \\
\hline $18-24$ & -622.3 \\
\hline $25-34$ & -715.0 \\
\hline $35-44$ & -474.8 \\
\hline $45-54$ & 38.18 \\
\hline $55-64$ & $404.2^{\mathrm{b}}$ \\
\hline \multicolumn{2}{|l|}{ Female } \\
\hline $18-24$ & -645.7 \\
\hline $25-34$ & -600.3 \\
\hline $35-44$ & -560.3 \\
\hline $45-54$ & -187.0 \\
\hline Squared age & 0.619 \\
\hline Smoker & -179.3 \\
\hline White & -149.4 \\
\hline African-American & $-921.3^{c}$ \\
\hline Hispanic & -422.5 \\
\hline Family income & $0.0042^{c}$ \\
\hline \multicolumn{2}{|l|}{ Family education } \\
\hline High school grad & 207.4 \\
\hline Some college & 162.4 \\
\hline College grad & 262.8 \\
\hline Graduate school & 63.25 \\
\hline Metropolitan area & 210.3 \\
\hline New England & 101.1 \\
\hline Mid-Atlantic & 51.66 \\
\hline East S. Central & -62.94 \\
\hline West N. Central & -281.8 \\
\hline West S. Central & -171.7 \\
\hline South Atlantic & -82.00 \\
\hline Mountain & -154.7 \\
\hline Pacific & -252.1 \\
\hline Constant & $1550^{\mathrm{b}}$ \\
\hline
\end{tabular}

${ }^{a} N=740$, adjusted $R$-squared $=0.19$.

bignificant at $5 \%$.

'Significant at $1 \%$ or less. 


\section{Table 4.5}

Distribution of net predicted CTS premiums for uninsured individuals, under fixed $\$ 1,000$ tax credit plan

\begin{tabular}{lccc}
\hline & Predicted premium & Net premium (NP) & $\begin{array}{l}\text { NP as a percentage } \\
\text { of original premium }\end{array}$ \\
\hline Mean & $\$ 1,558$ & $\$ 619$ & 31 \\
10th percentile & $\$ 735$ & $\$ 0$ & 0 \\
25th percentile & $\$ 1,166$ & $\$ 166$ & 14 \\
50th percentile & $\$ 1,519$ & $\$ 519$ & 34 \\
75th percentile & $\$ 1,864$ & $\$ 864$ & 46 \\
90th percentile & $\$ 2,475$ & $\$ 1,475$ & 60 \\
\hline
\end{tabular}

Representative sample of 6,083 uninsured individuals in the CTS household survey (1996-1997). Premiums are predicted from estimated coefficients in a regression of nongroup policyholder premiums on characteristics (see table 4.4).

\section{Simulating Underwriting}

The estimates using the web data show the premiums that individuals would see if they searched the relevant part of the web site, but the process of obtaining coverage requires more than just agreeing to buy at one of those proposed premiums. (The estimates based on the CTS "purchasing" sample already include any higher premiums based on underwriting.) For new purchases of insurance (but not for renewals), individuals must apply for coverage and will be asked questions about health status and use of medical services in the recent past. If an individual provides answers that suggest high risk, the insurer may decline to insure or may propose a higher premium. While some high-risk individuals obtain individual insurance coverage at premiums that do not differ from the average, some do not. ${ }^{12}$

To simulate the operation of an underwriting process, we assume that uninsured individuals in the CTS survey who report their health on the survey to be "poor" or "fair" (whatever they might tell an insurer), or who report that they were ever denied coverage, will be faced with the premium in the 90 th percentile of the distribution of premiums for persons with their characteristics. Of the 4,352 individuals in the sample, 895 (18 percent) report that they were in poor or fair health, and 202 report that they were ever denied coverage. Because of overlap, the net proportion of the sample thus classified as "high risk" is 21 percent.

Table 4.6 modifies table 4.3 based on these assumptions. It is still true that more than one-quarter of all uninsured would face zero net 
Table 4.6

Distribution of net premiums after underwriting, under fixed $\$ 1,000$ tax credit plan

\begin{tabular}{lccc}
\hline & Online premium & Net premium (NP) & $\begin{array}{l}\text { NP as a percentage } \\
\text { of original premium }\end{array}$ \\
\hline Mean & $\$ 1,849$ & $\$ 936$ & 31 \\
10th percentile & $\$ 663$ & $\$ 0$ & 0 \\
25th percentile & $\$ 831$ & $\$ 0$ & 0 \\
50th percentile & $\$ 1,390$ & $\$ 390$ & 28 \\
75th percentile & $\$ 2,436$ & $\$ 1,436$ & 59 \\
90th percentile & $\$ 3,962$ & $\$ 2,962$ & 75 \\
\hline
\end{tabular}

Representative sample of uninsured individuals in the CTS household survey (1996-1997). For each individual who reported no denial of coverage and good to excellent health, the online premium reflects the 25 th percentile premium for a menu of individual health insurance plans in the corresponding locale. Those individuals (approximately 20 percent of the sample) who reported fair or poor health or denial of coverage were matched to the 90 th percentile premium. Premium quotes were obtained from www.ehealthinsurance.com.

premiums, but the net premium at the 50th percentile rises a moderate amount, to $\$ 390$. The proportion who would be classified as high risk by these assumptions is larger than the proportion of applicants insurers estimate they would classify in this way. ${ }^{13}$ But probably many high risks do not apply for insurance, both because they would not expect to be quoted premiums they would be willing to pay and because high risk especially characterizes low-income uninsured, who would often not pay even average-risk premiums.

\section{Predicting Purchase}

We now wish to determine whether uninsured individuals facing the distribution of net premiums described above would be willing to buy coverage. To produce estimates of such take-up rates, we use two simulation techniques described in Pauly and Herring. ${ }^{14}$ One technique constructs the distribution of the reservation prices directly and assumes an individual will obtain coverage if the individual's reservation price exceeds the net premium he or she faces. The other technique estimates an individual's probability of obtaining insurance as a function of the net premium; this model is derived from the observed relationship between coverage and net loading in the employment-based setting.

For our first approach, we construct a "synthetic" estimate of a reservation price for insurance for an uninsured individual based on his or 
her change in expected expenses for being insured relative to being uninsured. Specifically, one's willingness to pay for insurance is specified as the sum of the expected decrease in out-of-pocket expense, the Arrow-Pratt risk premium paid for the decrease in the variation in out-of-pocket expense, the increase in consumer surplus from consuming more medical care, and the reduction in disutility felt from free care when uninsured. We set the Arrow-Pratt absolute risk aversion coefficient equal to 0.00095 and assume that the increase in consumer surplus equals half of the difference in total expenditures. Further, we assume that the disutility associated with being a charity care patient equals 20 cents per dollar of free care received; for more detail regarding results generated from varying this assumption, see Pauly and Herring (forthcoming).

Since the CTS lacks detailed data for medical expenses, we first developed a distribution of reservation prices for a sample of individuals in the 1996 Medical Expenditure Panel Survey (MEPS). After inflating this data to 2001 dollars, we then assigned that distribution of reservation prices to the uninsured CTS sample by randomly selecting a reservation price from an MEPS subsample of individuals with similar age, gender, and self-reported health status.

Table 4.7 shows the distributions of reservation prices of the uninsured for three separate plans that were the most common of those found online. The first is a PPO plan with a $\$ 1,000$ deductible, 20 percent coinsurance, and a $\$ 2,000$ upper limit on out-of-pocket spending. The second is a similar plan with a $\$ 500$ deductible, and the third has a $\$ 250$ deductible. The assumptions we make for estimating an individual's reservation price for a particular plan are those that we presented in the midrange case presented in Pauly and Herring. ${ }^{15}$ As seen in the table, the median uninsured individual would be willing to pay $\$ 592$ for a $\$ 1,000$ deductible PPO plan, $\$ 707$ for a $\$ 500$ deductible plan, and $\$ 787$ for a $\$ 250$ deductible plan; these distributions are considerably skewed.

To examine the level of subsidy required to induce the uninsured to purchase insurance, we show the distribution of the difference between an individual's reservation price and the premium he or she faces. Table 4.8 shows the distribution of subsidies needed when we assume that the premium faced by an uninsured individual is at the 10 th percentile of premiums quoted in our automated online search. The last three lines of this table show the percentile at which the difference between our estimated reservation price and the premium they face falls below $\$ 1,000$. For example, we find that 85 percent of the unin- 
Table 4.7

Distribution of reservation prices for insurance, using an expected utility framework ${ }^{a}$

\begin{tabular}{lccc}
\hline & $\$ 1,000$ deductible & $\$ 500$ deductible & $\$ 250$ deductible \\
\hline Mean & $\$ 1,106$ & $\$ 1,245$ & $\$ 1,353$ \\
10th percentile & $\$ 176$ & $\$ 240$ & $\$ 290$ \\
25th percentile & $\$ 312$ & $\$ 395$ & $\$ 469$ \\
50th percentile & $\$ 592$ & $\$ 707$ & $\$ 787$ \\
75th percentile & $\$ 1,332$ & $\$ 1,513$ & $\$ 1,647$ \\
90th percentile & $\$ 2,612$ & $\$ 2,900$ & $\$ 3,126$ \\
\hline
\end{tabular}

${ }^{a}$ Details of these simulations are provided in the text.

Table 4.8

Distribution of subsidies required for the purchase of insurance (assuming premiums obtained are at the 10 th percentile) ${ }^{\mathrm{a}}$

\begin{tabular}{lccc}
\hline & $\$ 1,000$ deductible & $\$ 500$ deductible & $\$ 250$ deductible \\
\hline Mean & $\$ 534$ & $\$ 1,176$ & $\$ 1,615$ \\
10th percentile & $\$ 0$ & $\$ 0$ & $\$ 0$ \\
25th percentile & $\$ 0$ & $\$ 0$ & $\$ 487$ \\
50th percentile & $\$ 168$ & $\$ 316$ & $\$ 1,464$ \\
75th percentile & $\$ 608$ & $\$ 880$ & $\$ 2,312$ \\
90th percentile & $\$ 1,480$ & $\$ 1,966$ & $\$ 3,524$ \\
85th percentile & $\$ 1,000$ & $\mathrm{NA}$ & $\mathrm{NA}$ \\
78th percentile & $\mathrm{NA}$ & $\$ 1,000$ & $\mathrm{NA}$ \\
34th percentile & $\mathrm{NA}$ & $\mathrm{NA}$ & $\$ 1,000$ \\
\hline
\end{tabular}

a Details of these simulations are provided in the text.

sured sample requires a subsidy of under $\$ 1,000$ for the purchase of a $\$ 1,000$ deductible PPO plan, while only 34 percent of the uninsured would respond to such a subsidy for purchase of a $\$ 250$ deductible plan. If we assume that all of those for whom the net premium falls below their reservation price were to obtain coverage, the take-up rate of a $\$ 1,000$ credit for a $\$ 1,000$ deductible PPO would be 85 percent. Table 4.9 shows the distribution of subsidies needed when we assume instead that individuals are able to obtain premiums only at the 25 th percentile of those quoted for their specific age, gender, and location. The subsidies reported here are larger.

Our expected utility model generates reservation prices for insurance for the minority that fall below the unsubsidized premium (we assume that) they face currently. We therefore present take-up rates of a 
Table 4.9

Distribution of subsidies required for the purchase of insurance (assuming premiums obtained are at the 25th percentile)

\begin{tabular}{|c|c|c|c|}
\hline & $\$ 1,000$ deductible & $\$ 500$ deductible & $\$ 250$ deductible \\
\hline Mean & $\$ 741$ & $\$ 1,580$ & $\$ 1,678$ \\
\hline 10th percentile & $\$ 0$ & $\$ 0$ & $\$ 0$ \\
\hline 25th percentile & $\$ 0$ & $\$ 156$ & $\$ 638$ \\
\hline 50 th percentile & $\$ 390$ & $\$ 866$ & $\$ 1,518$ \\
\hline 75th percentile & $\$ 951$ & $\$ 1,500$ & $\$ 2,379$ \\
\hline 90th percentile & $\$ 2,044$ & $\$ 2,798$ & $\$ 3,583$ \\
\hline 77th percentile & $\$ 1,000$ & NA & NA \\
\hline 57 th percentile & NA & $\$ 1,000$ & NA \\
\hline 32nd percentile & NA & NA & $\$ 1,000$ \\
\hline
\end{tabular}

Details of these simulations are provided in the text. Samples differ slightly due to the unavailablity of certain plans in a few markets.

$\$ 1,000$ credit using this "implied" take-up rate of unsubsidized insurance as our baseline. For instance, we observe that the 10th per-centile "net" premium (i.e., the "absolute" premium minus the $\$ 1,000$ credit) for the $\$ 1,000$ deductible PPO plan is less than our simulated reservation price for 85 percent of our sample of currently-uninsured individuals. However, the 10th percentile of the "absolute" premium is actually less than the reservation price we produced for 23 percent of this sample of uninsured. We therefore present overall take-up rates using as a baseline this 23 percent of uninsured that our model predicts would have already purchased unsubsidized insurance. That is, the overall take-up rate we present is equal to 62 percent, i.e., about 85 percent minus 23 percent.

Table 4.10 shows more detail on the take-up rates that we estimate for various assumptions about the plans facing the uninsured. If we assume instead that the uninsured face the 25 th percentile of premiums for a $\$ 1,000$ deductible PPO, we estimate a lower take-up rate of 56 percent. Assuming that the $\$ 1,000$ credit is made available only to a more generous $\$ 250$ deductible PPO, we estimate a reduction in the uninsured of only 21 percent when we also assume that an individual faces the premium at the 25 th percentile of online quotes. If we use instead the individual's predicted premium from the CTS nongroup sample of purchases, we estimate a take-up rate of 43 percent. For this final case, the distribution of reservation prices we apply is that for the typical nongroup plan seen in the CTS followback data. 
Table 4.10

Take-up rates of private insurance given a $\$ 1,000$ refundable tax credit ${ }^{\mathrm{a}}$

\begin{tabular}{|c|c|c|}
\hline Premium assumption & $\begin{array}{l}\text { Reservation } \\
\text { price approach }\end{array}$ & $\begin{array}{l}\text { Net loading } \\
\text { approach }\end{array}$ \\
\hline $\begin{array}{l}\text { Internet premiums, } 10 \text { th percentile (of } \$ 1,000 \\
\text { deductible plans) }\end{array}$ & $62 \%$ & $85 \%$ \\
\hline $\begin{array}{l}\text { Internet premiums, } 25 \text { th percentile (of } \$ 1,000 \\
\text { deductible plans) }\end{array}$ & $56 \%$ & $77 \%$ \\
\hline $\begin{array}{l}\text { Internet premiums, } 25 \text { th percentile (of } \$ 250 \\
\text { deductible plans) }\end{array}$ & $21 \%$ & $32 \%$ \\
\hline Predicted CTS nongroup premiums & $43 \%$ & $61 \%$ \\
\hline
\end{tabular}

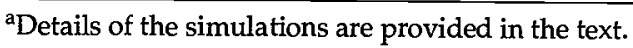

The second column of table 4.10 shows the results generated from applying a second estimation technique described in Pauly and Herring. ${ }^{16}$ This second technique instead estimates a reduced-form version of the demand for insurance to produce an individual's likelihood of obtaining coverage as a function of the net price she or he faces. Specifically, using the MEPS data for workers and their dependents, we estimated a probit model for the probability of purchasing insurance as a function of one's age, gender, income, education, race, region, and the net price one faces. Defining this "net price" in the traditional sense as the administrative loading and as a percentage of expected benefits, we constructed values for net loading determined by household marginal tax rates and the administrative loading that coincides with the median firm size in the worker's industry. Thus, the coefficients from estimating this model for the probability of being insured as a function of these various controls and the net price of insurance allows us to simulate a new predicted probability of purchasing insurance given that uninsured individual's demographic controls and the "new" subsidized net price. Here too, however, the take-up rate for insurance must be specified as the change in predicted probabilities from the unsubsidized nongroup price to a subsidized one. If we consider the 25 th percentile of online quotes for a $\$ 250$ deductible PPO plan and assume nongroup administrative loading equal to 40 percent of premiums, we estimate a 32 percent take-up rate of a $\$ 1,000$ credit for that insurance. If instead we consider a $\$ 1,000$ deductible PPO plan, the fixed-dollar credit lowers the net loading considerably; here, we estimate a take-up rate of 77 percent. If we assume that the premium faced by an uninsured individ- 
ual is the one we generate from the average CTS nongroup premium, we estimate a reduction in the uninsured equal to 61 percent.

Overall, the take-up rates we estimate from our net loading approach are somewhat higher than those we estimate from our reservation price approach. As we argued before, however, this uncertainty-whether in the form of specifying a model or in the form of assuming what premiums the uninsured face-should be front and center in the evaluation of tax credit schemes because we, as analysts, have minimal experience with large subsidies directed at low-income individuals. ${ }^{17}$

\section{Discussion}

The results in this paper yield estimates of the effectiveness of a modest tax credit in reducing the number of a representative sample of uninsured that are consistent with, but somewhat more optimistic than, our earlier conjectures, largely because the premiums we estimate or use in this paper are generally lower than those used earlier. If the 10th percentile web site premiums represent genuine offers to sell insurance, the results are even more optimistic. While many of the low-risk uninsured face low or zero premiums, however, the minority of people who are high risk will still pay high net premiums. Our simulations indicate that even many of these older or higher risks would be willing to pay higher premiums because the alternative is to pay large amounts out of pocket or put up with less attractive charity care. The main conclusion, as we have noted before, is that fixed dollar premiums are less effective than proportional or risk-adjusted premiums at getting a smaller number of higher risks covered, but they are more effective for the larger number of lower risks. Indeed, without additional risk-adjusted credits or a high-risk pool, it is unlikely that insurers will insure truly high risks who seek coverage for explicitly acknowledged active medical conditions.

Why do our results in this paper differ somewhat from our earlier findings? It is possible that web premiums tend to be lower than actual transactions premiums for people who did not use the web. Maybe the benchmark loading estimates, which are based on aggregate premiums and benefits for a set of large commercial insurers, are overestimates. The Blue plans, which are active in the nongroup market, were left out of some of these benchmark measures, as were some smaller commer- 
cial insurers, and accident insurance was included with health insurance.

The key remaining unknown for our study and all others, however, is how underwriting affects the premiums people actually pay (not what insurers quote). Our previous work indicated that many buyers with a history of prior chronic conditions were able to avoid paying unusually high premiums and were still able to obtain coverage. But the nature of the interplay between sellers trying to charge high premiums to high (and low) risks, and buyers searching for reasonable options, is unknown.

Current nongroup health insurance premiums are not set in expectation of purchases by a large number of formerly uninsured persons armed with tax credits. Such a surge in demand would cause a profound transformation of this small and sleepy market. What effects might it have on premiums and coverage? We think it is likely that it would lead to lower administrative costs and less severe problems of adverse selection than nongroup insurers currently face, both because of sheer volume and because most of these new purchasers would tend to be average risks who are strongly motivated to seek coverage with little selling effort needed. If these conjectures are right, the final outcome could be even more optimistic than the estimates presented here. It is also possible, however, that cautious insurers might respond by raising premiums in the face of what is perceived as a more risky (or at least different) market. Tax credits would put a heavy obligation on nongroup insurers to offer attractive policies at affordable net premiums.

\section{Notes}

Research was supported by a grant from The Leon Lowenstein Foundation.

1. Pauly and Herring 2001.

2. Pauly and Herring 1999.

3. Pauly and Herring 2001; Frogue 2001; eHealthInsurance.com 2001a, eHealthInsurance.com 2001b, eHealthInsurance.com 2001c, eHealthInsurance.com 2001d.

4. Pauly and Herring 1999.

5. Frogue 2001.

6. Lav and Friedman 2001.

7. Pollitz, Sorian, and Thomas 2001. 
8. Trude and Ginsburg 2001.

9. Shactman and Altman 2000.

10. Pauly and Herring, forthcoming.

11. We also used standard errors of prediction to construct 95 percent confidence intervals for expected premiums, conditional on individual characteristics. Because the errors tend to cancel out, we would not expect that the prediction error matters much to the distribution of net premiums. We varied the distribution of predicted premiums through random draws of these intervals or through the application of the intervals' lower and upper bounds. We conclude that the intervals are small because they do not affect the overall interpretation of the original distribution of predicted premiums.

12. Pauly and Herring 1999.

13. Chollet and Kirk 1998.

14. Pauly and Herring, forthcoming.

15. Pauly and Herring 2001.

16. Pauly and Herring, forthcoming.

17. Pauly and Herring 2001.

\section{References}

Chollet, D., and A. Kirk (1998). Understanding Individual Health Insurance Markets: Structure, Practices, and Products in Ten States. Menlo Park, CA: Henry J. Kaiser Family Foundation.

eHealthInsurance.com (2001a). "Letter to Congress: eHealthInsurance Endorsement of the 'Reach' Act," March 14, 2001. http:// www.ehealthinsurance.com/ehealthinsurance/ Press.html (June 12, 2001).

eHealthInsurance.com (2001b). "Press Release: eHealthInsurance Supports U.S. Senators on Bipartisan 'Reach' Act to Help Uninsured Americans," March 14, 2001. http://www. ehealthinsurance.com/ehealthinsurance/Press.html (June 12, 2001).

eHealthInsurance.com (2001c). "Letter to Congress: eHealthInsurance Endorsement of the Fair Care for the Uninsured Act," April 3, 2001. http://www.ehealthinsurance. com/ehealthinsurance/Press.html (June 12, 2001).

eHealthInsurance.com (2001d). "Press Release: eHealthInsurance Supports Congress' Bipartisan Tax Credit Provisions in the Fair Care for the Uninsured Act," April 3, 2001. http://www.ehealthinsurance.com/ehealthinsurance/Press.html (June 12, 2001).

Frogue, J. (2001). "Recent Survey Points to Affordable Individual Health Insurance." The Heritage Foundation Executive Memorandum, No. 740 (April 17).

Lav, I., and J. Friedman (2001). "Tax Credits for Individuals to Buy Health Insurance Won't Help Many Uninsured Families." Center on Budget and Policy Priorities Report (February 15$)$.

Pauly M., and B. Herring (1999). Pooling Health Insurance Risks, Washington, D.C.: AEI Press. 
Pauly, M., and B. Herring (2001). "Expanding Insurance Coverage Through Tax Credits: Tradeoffs and Options." Health Affairs 20(1):1-18.

Pauly, M., and B. Herring (forthcoming). Options and Effects of Tax Credits for Health Insurance. Washington, D.C.: AEI Press.

Pollitz, K., R. Sorian, and K. Thomas (2001). How Accessible Is Individual Health Insurance for Consumers in Less-Than Perfect Health? Menlo Park, CA: Henry J. Kaiser Family Foundation, June.

Shactman, D., and S. Altman (2000). "The United States Confronts the Policy Dilemmas of an Aging Society." Health Affairs 19(3):252-258.

Trude, S., and P. Ginsburg (2001). "Tax Credits and Purchasing Pools: Will This Marriage Work?" Center for Studying Health System Change, Issue Brief No. 36 (April). 